\title{
OPEN Alpha-2-macroglobulin from circulating exosome-like vesicles is increased in women with preterm pregnancies
}

Júlia A. Tronco ${ }^{1}$, Bruna R. de A. Ramos ${ }^{1}$, Natália M. Bastos ${ }^{2}$, Sérgio A. Alcântara ${ }^{3}$, Juliano C. da Silveira² \& Márcia G. da Silva ${ }^{1 \bowtie}$

Preterm labor (PTL) and Preterm Premature Rupture of Membranes (PPROM) impose substantial morbimortality on mothers and newborns. Exosomes act in intercellular communication carrying molecules involved in physiopathological processes. Little is known about exosomal proteins in prematurity. Our aim was to evaluate the protein expression of hemopexin, $\mathrm{C} 1$ inhibitor (C1INH) and alpha-2-macroglobulin (A2M) from circulating exosomes of women with PTL and PPROM. Plasma was obtained from PTL, PPROM, Term in labor and Term out of labor (T) patients, exosomes were isolated by ultracentrifugation, then lysed and the proteins quantified. Western Blot (WB) and Nanoparticle Tracking Analysis (NTA) were performed. Data were compared by Kruskal-Wallis, unpaired T-test and one-way ANOVA. WB and NTA confirmed exosome isolation (concentration: $4.3 \times 10^{10}$ particles/ $\mathrm{ml} \pm 1.9 \times 10^{10}$ ). There was no difference regarding hemopexin or C1INH expression between the groups. For $\mathrm{A} 2 \mathrm{M}$, the fold change was significantly higher on preterm groups when compared to term groups $(1.07 \pm 0.30$ vs. $0.42 \pm 0.17, p<0.0001)$. Higher levels of A2M in circulating exosomes are linked to preterm pregnancies. $s E V$ are strong candidates to intermediate maternal-fetal communication, carrying preterm labor-related immunomodulatory proteins.

Preterm labor (PTL) is defined by labor before the 37 th week of gestation and affects about $10 \%$ of all pregnancies, representing a global public health challenge ${ }^{1-3}$. Preterm birth, a consequence of this condition, is the main cause of neonatal and infant morbidity and mortality. Another obstetric complication associated with PTL that can aggravate maternal and fetal morbimortality is Preterm Premature Rupture of Membranes (PPROM). PPROM is characterized by the rupture of fetal membranes before 37 weeks of pregnancy and can be identified in $30-40 \%$ of PTL cases ${ }^{4}$.

Molecularly, mechanisms of inflammation, oxidative stress and autophagy are known to be directly involved in PTL and PPROM pathogeny ${ }^{5-7}$. Nevertheless, there are still no reliable biomarkers capable of predicting such conditions. This difficulty is due to the complexity that involves the interactions between maternal and fetal compartments and the difficulty to obtain good markers from relatively not invasive biological samples.

Promisingly in this field, extracellular vesicles from maternal circulation, especially small extracellular vesicles enriched in exosomes (sEV), may enclose potential biomarkers for gestational complications. Exosomes have a circled and flatted shape, are composed of a lipid bi-layer ${ }^{8}$ and their diameter varies between 30 and $150 \mathrm{~nm}^{9}$. Earlier described as a cellular elimination mechanism, the exosomes have started to stand out as a finely regulated mechanism of intercellular communication ${ }^{9}$. Furthermore, one outstanding characteristic of such vesicles is their high stability, as they maintain their integrity even after thawing ${ }^{10}$.

Recent reports show the importance of these vesicles in intercellular communication also during the gestational period. The trophoblastic and placental cells secrete sEV and it has already been demonstrated that its concentration enhances significantly over the gestational trimesters and is significantly higher on pregnant women when compared to non-pregnant individuals ${ }^{11}$.

sEV carry many molecules such as nuclear, cytosolic and membrane proteins, lipids, and RNAs. Some of the proteins already described to be contained in exosomes are the tetraspanins (global markers), like CD63,

${ }^{1}$ Department of Pathology, Botucatu Medical School, São Paulo State University (UNESP), Botucatu, SP, Brazil. ${ }^{2}$ Department of Veterinary Medicine, Faculty of Animal Science and Food Engineering, São Paulo University (USP), Pirassununga, SP, Brazil. ${ }^{3}$ Department of Mophology, Biosciences Institute, São Paulo State University (UNESP), Botucatu, SP, Brazil. ${ }^{\circledR}$ email: marcia.guimaraes@unesp.br 


\begin{tabular}{|c|c|c|c|c|c|}
\hline Variables & PTL $(n=9)$ & PPROM $(\mathbf{n}=7)$ & TL $(\mathbf{n}=8)$ & Term $(n=10)$ & $p$ \\
\hline Maternal age (years)* & $25.7 \pm 4.0$ & $269 \pm 7.0$ & $23.1 \pm 4.8$ & $29.5 \pm 4.7$ & NS \\
\hline GA at delivery (days)* & $244.8 \pm 20^{\mathrm{a}}$ & $231.7 \pm 26^{\mathrm{a}}$ & $279 \pm 9^{\mathrm{b}}$ & $272 \pm 3.7^{\mathrm{b}}$ & $<0.0001$ \\
\hline BMI $\left(\mathrm{kg} / \mathrm{h}^{2}\right)^{*}$ & $26.6 \pm 3.5$ & $29.1 \pm 6.7$ & $26.9 \pm 2.8$ & $28.9 \pm 4.8$ & NS \\
\hline \multicolumn{6}{|l|}{ Delivery (\%) } \\
\hline Vaginal & $71.4(5 / 7)$ & $66.6(4 / 6)$ & $50(4 / 8)$ & - & 0.0096 \\
\hline Caesarean & $28.6(2 / 7)$ & $33.4(2 / 6)$ & $50(4 / 8)$ & $100(10 / 10)$ & \\
\hline \multicolumn{6}{|l|}{ Marital status (\%) } \\
\hline Single & $11(1 / 9)$ & $71(5 / 7)$ & - & - & 0.0004 \\
\hline Civil union & $89(7 / 9)$ & $29(2 / 7)$ & $100(7 / 7)$ & $100(9 / 9)$ & \\
\hline \multicolumn{6}{|c|}{ Self-reported ethnicity (\%) } \\
\hline White & $78(7 / 9)$ & $57(4 / 7)$ & $14(1 / 7)$ & $60(6 / 10)$ & NS \\
\hline Non White & $22(2 / 9)$ & $43(3 / 7)$ & $86(6 / 7)$ & $40(4 / 10)$ & \\
\hline \multicolumn{6}{|l|}{ Parturity (\%) } \\
\hline First pregnancy & $33(3 / 9)$ & $43(3 / 7)$ & $71(5 / 7)$ & $40(4 / 10)$ & NS \\
\hline Multiple pregnancy & $67(6 / 9)$ & $57(4 / 7)$ & $29(2 / 7)$ & $60(6 / 10)$ & \\
\hline \multicolumn{6}{|l|}{ Smoking (\%) } \\
\hline Smoking & $11(1 / 9)$ & $14(1 / 7)$ & - & $10(1 / 10)$ & NS \\
\hline Non smoking & $89(8 / 9)$ & $86(6 / 7)$ & $100(8 / 8)$ & $90(9 / 10)$ & \\
\hline \multicolumn{6}{|l|}{ Years of study (\%) } \\
\hline$<8$ years & - & $14(1 / 7)$ & - & $11(1 / 9)$ & NS \\
\hline$\geq 8$ years & $100(8 / 8)$ & $86(6 / 7)$ & $100(7 / 7)$ & $89(8 / 9)$ & \\
\hline \multicolumn{6}{|c|}{ Previous history of PTL/PPROM (\%) } \\
\hline Presence & $33(3 / 9)$ & $14(1 / 7)$ & - & $11(1 / 9)$ & \\
\hline Absence & $67(6 / 9)$ & $86(6 / 7)$ & $100(8 / 8)$ & $89(9 / 9)$ & NS \\
\hline \multicolumn{6}{|l|}{ Prior abortion (\%) } \\
\hline Presence & $33(3 / 9)$ & $14(1 / 7)$ & - & $20(2 / 10)$ & NS \\
\hline Absence & $67(6 / 9)$ & $86(6 / 7)$ & $100(7 / 7)$ & $80(8 / 10)$ & \\
\hline
\end{tabular}

Table 1. Sociodemographic data from patients included in the study. The letters 'a' and 'b' represent statistical differences. PTL preterm labor, PPROM Preterm Premature Rupture of Membranes, TL term in labor, GA gestational age, $B M I$ body mass index, NS non-significant $(p>0.05) .{ }^{\star}$ Data represented by mean \pm standard deviation and compared by ANOVA. Qualitative variables were analyzed by Chi-square.

CD81 and CD9, EGFR proteins and major histocompatibility complex MHC I and II (originated from antigenpresenting cells), as well as other transmembrane proteins (LAMP1, TFR).

On the prematurity context, little is known about the relevance of microvesicle's proteins and the development of PTL and PPROM. Menon et al. ${ }^{12}$ recently established the protein content of maternal plasma exosomes and demonstrated a correlation between the protein's pathway and preterm and term birth's mechanism. A report by Cantonwine et al. ${ }^{13}$ demonstrated that out of 132 protein evaluated from circulating microvesicles from women on the first trimester of pregnancy, 20 were related to term labor as protection factors or were risk factors for preterm labor. Three of these proteins were already described to be enclosed by exosomes (ExoCarta), stand out for their potential correlation with prematurity: hemopexin, $\mathrm{C} 1$ inhibitor (C1INH), and alpha-2-macroglobulin (A2M).

Considering the importance of sEV to pregnancy along with their characteristics of specificity, stability, and accessibility, it becomes evident the need to investigate molecules contained in these vesicles in women with unfavorable pregnancy outcomes, once these molecules have the potential to predict pathologies in the future and to be used therapeutically. We hypothesize that the proteins hemopexin, C1INH and A2M are differently expressed in circulating sEV from women on the third trimester with PTL or PPROM.

\section{Results}

The sociodemographic data of the patients enrolled in the study are presented in Table 1 . As expected, the mean gestational age was significantly higher for the term groups when compared to the preterm groups $(275.0 \pm 7.4$ vs $239.1 \pm 23, p<0.0001$ ). There was a significant difference also in the way of delivery and marital status between the groups. Vaginal delivery represented $71.4 \%$ of PTL, $66.6 \%$ of PPROM and $50 \%$ of TL, all term women out of labor underwent caesarian section. As for marital status, $89 \%$ of PTL, 19\% of PPROM and 100\% of TL and T reported being in a civil union. There was no significant difference between the groups regarding the variables: maternal age, BMI, ethnicity, parity rate, smoking, years of study, previous history of PTL or PPROM and previous abortion (Table 1). 


\begin{tabular}{|c|c|c|c|c|c|}
\hline Variables & PTL $(n=9)$ & PPROM $(\mathbf{n}=7)$ & TL $(n=8)$ & Term $(n=10)$ & $p$ \\
\hline Weight $(\mathrm{g})^{*}$ & $2362 \pm 630.4^{\mathrm{a}}$ & $2266 \pm 419.5^{\mathrm{a}}$ & $3240 \pm 421.1^{\mathrm{b}}$ & $3319 \pm 460.0^{\mathrm{b}}$ & 0.0003 \\
\hline Apgar $10^{*}$ & $9.3 \pm 0.8$ & $8.8 \pm 0.8$ & $9.7 \pm 0.5$ & $9.7 \pm 0.5$ & NS \\
\hline \multicolumn{6}{|l|}{ Sex (\%) } \\
\hline Female & $33.3(3 / 9)$ & $28.6(2 / 7)$ & $50(4 / 8)$ & $60(6 / 10)$ & NS \\
\hline Male & $66.7(6 / 9)$ & $71.4(5 / 7)$ & $50(4 / 8)$ & $40(4 / 10)$ & \\
\hline
\end{tabular}

Table 2. Newborn clinical data of the patients included in the study. The letters 'a' and 'b' represent statistical differences. PTL preterm labor, PPROM Preterm Premature Rupture of Membranes, TL term in labor, NS nonsignificant $(p>0.05)$. ${ }^{\star}$ Data represented by mean \pm standard deviation and compared by ANOVA.
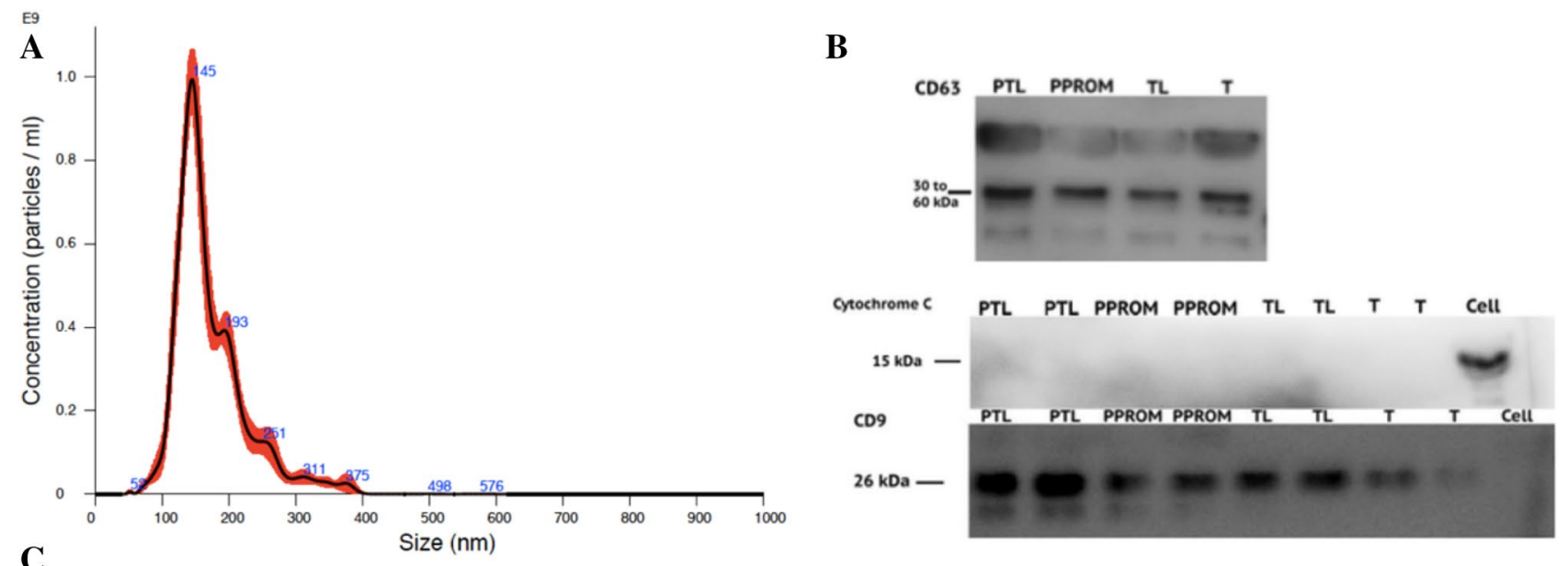

C

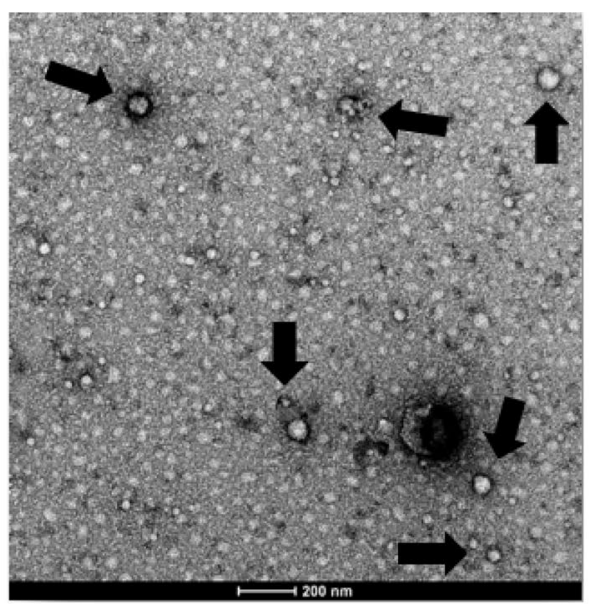

Figure 1. Characterization of exosome isolated from plasma. (A) The size distribution of sEV isolated from plasma. (B) Representative Western Blot for exosome marker CD63 and CD9 and negative marker Cytochrome C. (C) Transmission Electron Microscopy confirming the presence of sEV and its morphology characterization.

Regarding neonatal data, weight at birth was significantly higher among the term groups when compared to preterm groups and there was no significant difference between groups for Apgar score 10 and newborn gender (Table 2).

Successful sEV isolation was confirmed by Nanoparticle Tracking Analysis and Western Blot. The overall mean of particle's mode size was $148.0 \mathrm{~nm} \pm 27.5$, a size compatible with $\mathrm{sEV}$ characterization, and the mean particle's concentration was $4.3 \times 10^{10}$ particles $/ \mathrm{ml} \pm 1.9 \times 10^{10}$. There was no statistical difference in size or concentration of total circulating sEV across the groups. The positive controls-CD63 and CD9-were identified and the negative control-cytochrome C-was confirmed to be absent by WB (Fig. 1). Data regarding protein quantification and NTA for each group are displayed in Table 3.

To analyze the sEV proteins from Western Blot gels (Fig. 2), the fold change comparison for each protein was performed between the four groups and no significant difference was observed between any of them for the three proteins of interest (Fig. 3A). Further analysis included the fold change comparison between Preterm 


\begin{tabular}{|l|l|l|l|l|}
\hline Group & $\boldsymbol{\mu g} / \mathbf{m l}$ & No. particles/ml & Mean $(\mathbf{n m})$ & Mode $(\mathbf{n m})$ \\
\hline PTL & 874.2 & $4.15 \times 10^{10}$ & 178.1 & 150.9 \\
\hline PPROM & 716.0 & $4.60 \times 10^{10}$ & 173.9 & 148.0 \\
\hline TL & 955.3 & $4.64 \times 10^{10}$ & 180.8 & 152.8 \\
\hline T & 656.3 & $4.12 \times 10^{10}$ & 173.2 & 143.5 \\
\hline
\end{tabular}

Table 3. Comparison of protein quantification and NTA data. Mean protein quantification using Pierce BCA Protein Assay and mean values of the parameters measured by NTA for each group.

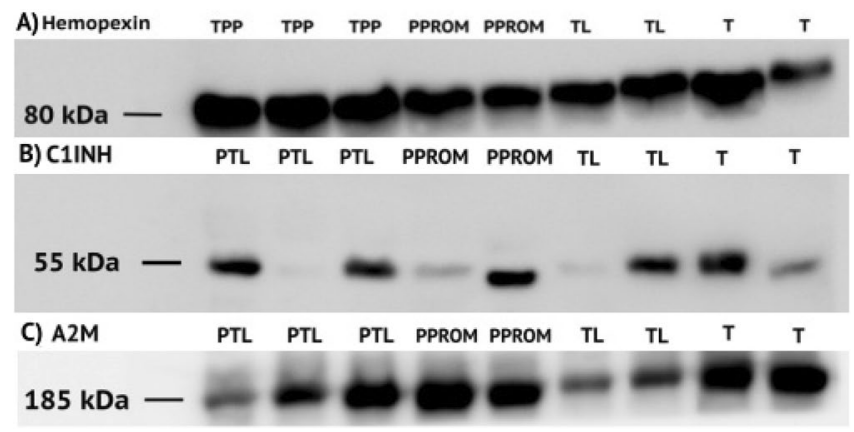

Figure 2. Western Blot for proteins of interest. (A) Representative WB for Hemopexin with $80 \mathrm{kDa}$. (B) Representative WB for C1INH with $55 \mathrm{kDa}$. (C) Representative WB for alpha-2-macroglobulin (A2M) with $185 \mathrm{kDa}$.

A

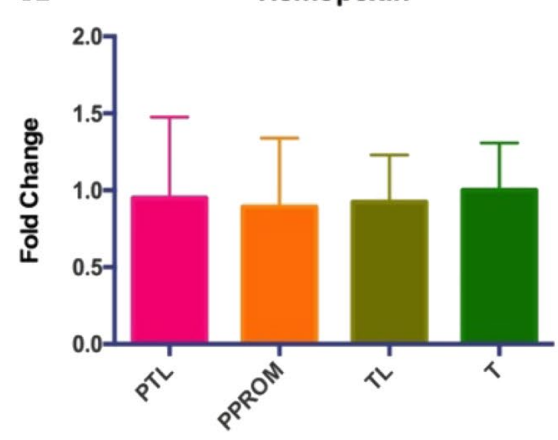

B

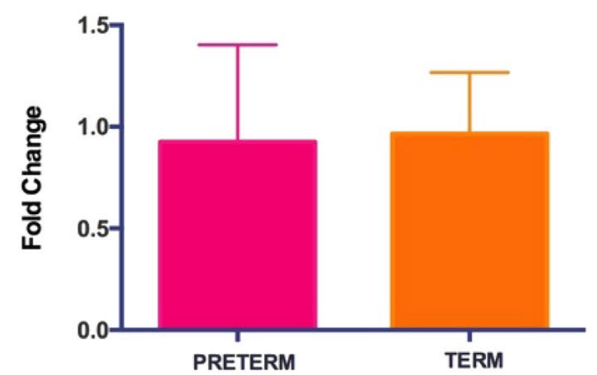

C1INH

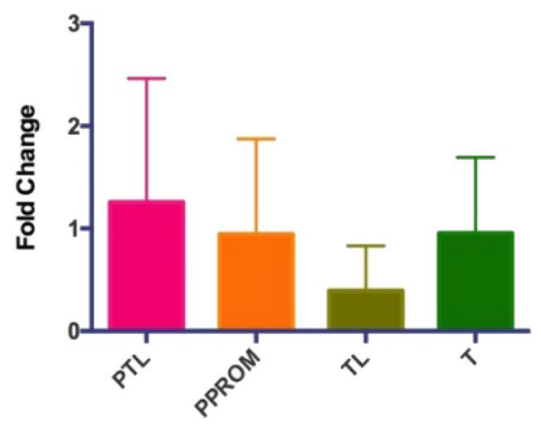

C1INH

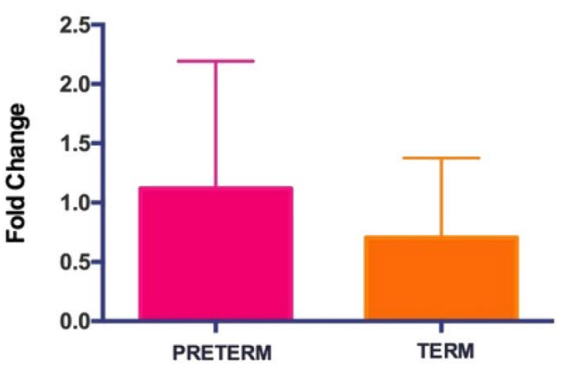

Alpha-2-macroglobulin

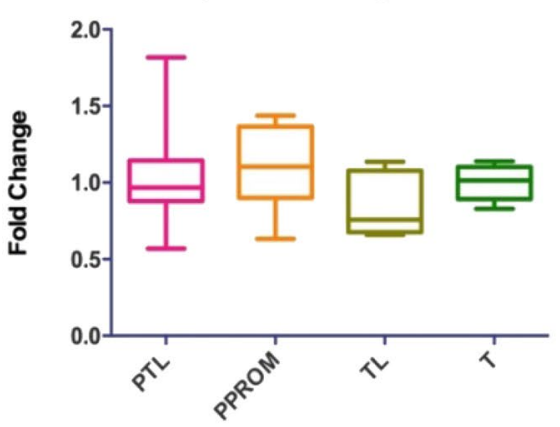

Alpha-2-macroglobulin

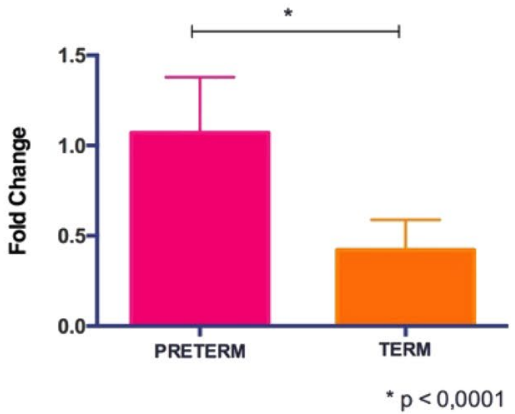

Figure 3. Expression of each protein of interest measured by fold change. (A) Hemopexin and C1INH were analyzed by One-Way ANOVA (bar graphs representation) and A2M by Kruskal-Wallis (box-whiskers representation). No significant difference was found $[p<0.05]$. (B) Preterm Groups (PTL + PPROM) and Term Groups $(\mathrm{TL}+\mathrm{T})$ were analyzed by $\mathrm{t}$-test. There was a significant difference in the expression of alpha-2macroglobulin, the protein was higher expressed on the Preterm Group when compared to the Term group $(p<0.001)$. 
groups $(\mathrm{PTL}+\mathrm{PPROM})$ and Term groups $(\mathrm{TL}+\mathrm{T})($ Fig. 3B). In this comparison, alfa-2-macroglobulin expression was significantly higher on preterm pregnancies compared to term $(1.07 \pm 0.30$ vs $0.42 \pm 0.17, p<0.0001)$.

\section{Methods}

Patients. Blood samples were collected at the Clinics Hospital from Botucatu Medical School and at the city's Basic Health Units, SP-Brazil, from January 2017 to August 2019. This research was approved by the Ethics Research Committee of our Institution (CAAE: 61138116.8.0000.5411). We confirm that this research was performed following relevant guidelines and regulations. Patients were included in four different groups: Preterm Labor (PTL), Preterm Premature Rupture of Membranes (PPROM), term in labor (TL), and term out of labor $(\mathrm{T})$. Patients were fasting for one hour and signed the research informed consent form. Exclusion criteria included major comorbidities such as diabetes mellitus, pre-eclampsia, arrhythmia, chorioamnionitis, placenta previa, or intake of anti-inflammatory drugs and insomnia.

Blood collection. Blood samples were collected from patients eligible for each group at the moment of their admission to the Obstetrics Services-PTL $(n=9)$, PPROM $(n=7)$, TL $(n=8)$, and T $(n=10)$-in sterile EDTA tubes. Blood collection followed the standard time-period prior defined for all samples (always between 9:30 a.m. and 10:30 a.m.) to standardize the results and the first 1-2 ml of blood was discarded, following the recommendation from the International Society for Extracellular Vesicles ${ }^{14}$. Plasma was obtained by centrifugation at $1800 \mathrm{~g}$ for $10 \mathrm{~min}$ and stored at $-80^{\circ} \mathrm{C}$ until further analysis.

Isolation of sEV. sEV's were isolated using aliquots of $1 \mathrm{ml}$ of plasma following the ultracentrifugation protocol adapted from Lässer et $\mathrm{al}^{15}$. First, samples were centrifuged at $20,000 \mathrm{~g}$ for $30 \mathrm{~min}$ to remove cell debris. Then, the supernatant was transferred to a falcon tube and diluted with $2 \mathrm{ml}$ of cold sterile phosphate-buffered saline (PBS). This mix was filtered using a sterile syringe filter with pore size $0.20 \mu \mathrm{m}$ and transferred to the ultracentrifugation tubes which, after balanced, were centrifuged at 120,000 $\mathrm{g}$ for $90 \mathrm{~min}$. At this stage, the supernatant was discarded and the pellet containing the sEV was resuspended in $200 \mu \mathrm{l}$ of cold sterile PBS and stored in sterile tubes at $-80^{\circ} \mathrm{C}$. All the centrifugation stages were performed at $4{ }^{\circ} \mathrm{C}$.

Nanoparticle Tracking Analysis. All samples were analyzed by Nanoparticle Tracking Analysis (NanoSight300). Samples were diluted in a 1:200 ratio and the parameters used for analysis were temperature $38.5^{\circ} \mathrm{C}$, $30 \mathrm{~s}$ capture, and 5 readings. Mode and concentration for each sample were given by the NanoSight software. Besides characterization, we hypothesized that the preterm birth (PTL and PPROM) could influence the sEV's size and concentration. To confirm or refute this hypothesis, both variables for each sample were analyzed by one way-ANOVA test and t-test.

Transmission Electron Microscopy. Transmission Electron Microscopy was performed to visually confirm sEV's isolation and to characterize its morphology.

Protein extraction and quantification. The buffer extraction containing Tris- $\mathrm{HCl}, \mathrm{NaCl}$, Triton $\times-100$, $\mathrm{CaCl}$ and protease inhibitor was added $(50 \mu \mathrm{l})$ to $100 \mu \mathrm{l}$ of exosomes resuspended in PBS, to lysate and extract the proteins. The isolated proteins were quantified by the Pierce BCA Assay kit (Thermo Scientific).

Western Blot. Western Blot was performed to identify two positives and one negative marker to confirm successful sEV isolation. As exosome's surface markers, CD9 and CD63 were used as positive controls and the mitochondrial marker Cytochrome $\mathrm{C}$ as a negative control. This technique was also performed to identify and quantify the proteins hemopexin, C1INH and A2M (Santa Cruz Biotechnology, Inc.) using the second antibody m-IgGK BP-HRP (Santa Cruz Biotechnology, Inc.). After protein quantification, $10 \mu \mathrm{l}$ of Mercaptoethanol and Laemmli Buffer $4 \times(1: 10$ ratio) were added to each sample ( $5 \mu \mathrm{g}$ of protein). The tubes containing samples and buffer (approximately $20 \mu$ l total volume) were heated to $95{ }^{\circ} \mathrm{C}$ on thermocycler for 5 min to denature the proteins. At this stage, molecular weight protein standard (Precision Plus Protein Dual Color Standards by Bio$\mathrm{Rad}$ ) and samples were loaded into the polyacrylamide gel. The technique's standards steps were followed and the nitrocellulose membranes were incubated with primary antibody overnight at $4{ }^{\circ} \mathrm{C}$ and then with secondary antibody for one hour and thirty minutes. The equipment ImageQuant 4000 was used for detection.

Image J and statistical analysis. The results obtained from Western Blot were analyzed by ImageJ. Normalization was performed in two steps. First, we normalized each sample's staining band area by its respective Ponceaus's staining band area (reference in Supplementary Material). Then, we normalized each result by the reference control samples' results (term group). We included at least two samples of each group for every gel. By this analys is a fold change for each protein of interest was provided. The data obtained was used to perform Kruskal-Wallis and One-Way ANOVA to compare the four groups and t-test to compare two groups (Preterm Groups vs. Term groups, PTL vs. TL or PPROM vs. T) on Prism 6 and statistical significance adopted was $5 \%$.

\section{Discussion}

Despite the scientific efforts to fully elucidate preterm birth markers and mediators, there are still many challenges to be overcome in the field. The investigation of specific proteins in circulating sEV is a new and promising approach. In this study, we were able to demonstrate higher expression of alpha-2-macroglobulin in 
preterm groups when compared to term groups. However, no significant difference regarding the expression of Hemopexin or C1INH was found between groups.

Hemopexin is a heme scavenger protein and has a complementary role to bind extracellular heme that is released as a metabolite when hemoglobin is degraded. It is mainly synthesized in the liver ${ }^{16}$. The usual concentration of hemopexin in plasma is $0.5-1 \mathrm{mg} / \mathrm{ml}$. However, this concentration can increase during inflammatory events, since hemopexin is an acute-phase protein, and its production is known to be regulated by the cytokines interleukin (IL)-6, IL-11, IL-1 $\beta$, leukemia inhibitory factor, oncostatin M, and tumor necrosis factor (TNF)- $\alpha^{17}$. As inflammatory syndromes, we expected to find higher levels of this protein on preterm samples, but there was no difference in hemopexin expression in the present study. Thus, it is worth to investigate other acute-phase proteins in the setting of PTL and PPROM.

The protein C1INH belongs to the SERPIN family and is responsible for inhibiting the spontaneous activation of $\mathrm{C} 1$ on complement activation. Consequently, it avoids overproduction of anaphylatoxins that act as inflammation mediators. According to Regal et al. ${ }^{18}$, deficiencies in specific complement regulators during pregnancy may predispose to excess complement activation and, conversely, several pregnancy complications including preterm birth have already been associated with excessive or misdirected complement activation ${ }^{18}$. Nevertheless, the relationship between the complement system and preterm labor is still controversial and poorly understood. While one study recently reported an association of this protein with PTL on 1st trimester samples but in an unexpected direction ${ }^{13}$, in our study C1INH was not differently expressed in third trimester preterm samples.

Alfa-2-macroglobulin functions as a broad-spectrum proteinase inhibitor. This protein is responsible for enhancing some procoagulant properties ${ }^{19}$. Besides, A2M can also bind to several cytokines, such as interleukin-6 (IL-6), Platelet-derived Growth Factor (PDGF), TNF- $\alpha$ and IL-1 $\beta$. Corroborating with Cantowine et al. ${ }^{13}$ that recently demonstrated an association between this protein and PTL as a risk factor, the protein A2M was significantly higher on preterm groups when compared to the term groups in our study. Also, according to Shimomura et al. ${ }^{19}$, A2M might play an important role in the interactions between several cytokines and the process of inflammation. Still, little is known about this protein in the prematurity context and even less regarding sEV. Future studies in distinct populations may further investigate the role of A2M as a potential biomarker on first trimester samples.

The main limitation of this study is that the technique used does not allow us to completely exclude the possibility of microvesicles contamination (particles larger than $200 \mathrm{~nm}$ ) or platelet derived-EV contamination (during the freeze-thaw process). While there are still no perfect isolation protocols for EVs, we were able to follow most of ISEV recommendations for sEV isolation and the possible presence of other particles does not undermine the value of this paper, as $\alpha 2 \mathrm{M}$ could be a biomarker of preterm birth regardless of particle size. Moreover, the technique used to quantify protein's expression, Western Blot, allows only a semi-quantitative analysis. Other techniques, such as liquid chromatography and mass spectrometry (LC/MS) could expand the knowledge in this field in future studies.

As preterm birth is still to be fully elucidated, the main strength of this study is that this is the first on our population to assess such conditions evaluating exosomal protein content. Follow up studies on this subject comparing total plasma proteins and EV proteins cargo may allow us to delve into the complex role of these vesicles in maternal-fetal communication.

We conclude that sEV are strong candidates to intermediate maternal and fetal communication, carrying immunomodulatory proteins, such as $\mathrm{A} 2 \mathrm{M}$, that can be related to preterm labor. Nevertheless, more studies that thoroughly investigate such proteins in the context of spontaneous prematurity are needed to extend this knowledge.

Received: 19 May 2020; Accepted: 18 September 2020

Published online: 12 October 2020

\section{References}

1. Selman, T. \& Johnston, T. Mechanisms and management of normal labour. Obstet. Gynaecol. Reprod. Med. 23(7), 208-213 (2013).

2. Norwitz, E. R. et al. Molecular regulation of parturition: the role of the decidual clock. Cold Spring Harb. Perspect. Med. 5(11), a023143. https://doi.org/10.1101/cshperspect.a023143 (2015).

3. Goldenberg, R. L., Culhane, J. F., Iams, J. D. \& Romero, R. Epidemiology and causes of preterm birth. Lancet 371(9606), 75-84 (2008).

4. Parry, S. \& Strauss, J. F. 3rd. Premature rupture of the fetal membranes. N. Engl. J. Med. 338(10), 663-670 (1998).

5. de Andrade Ramos, B. R. \& Witkin, S. S. The influence of oxidative stress and autophagy cross regulation on pregnancy outcome. Cell Stress Chaperones 21(5), 755-762 (2016).

6. Menon, R. Oxidative stress damage as a detrimental factor in preterm birth pathology. Front. Immunol. 5, 567 (2014).

7. Menon, R. \& Richardson, L. S. Preterm prelabor rupture of the membranes: a disease of the fetal membranes. Semin. Perinatol. 41(7), 409-419 (2017).

8. Thery, C., Zitvogel, L. \& Amigorena, S. Exosomes: composition, biogenesis and function. Nat. Rev. Immunol. 2(8), 569-579 (2002).

9. Abels, E. R. \& Breakefield, X. O. Introduction to extracellular vesicles: biogenesis, RNA Cargo selection, content, release, and uptake. Cell. Mol. Neurobiol. 36(3), 301-312 (2016)

10. Sarker, S. et al. Placenta-derived exosomes continuously increase in maternal circulation over the first trimester of pregnancy. J. Transl. Med. 12, 204 (2014).

11. Record, M. Intercellular communication by exosomes in placenta: a possible role in cell fusion?. Placenta 35(5), 297-302 (2014).

12. Menon, R. et al. Quantitative proteomics by SWATH-MS of maternal plasma exosomes determine pathways associated with term and preterm birth. Endocrinology 160(3), 639-650 (2019).

13. Cantonwine, D. E. et al. Evaluation of proteomic biomarkers associated with circulating microparticles as an effective means to stratify the risk of spontaneous preterm birth. Am. J. Obstet. Gynecol. 214(5), 631 (2016).

14. Witwer, K. W. et al. Standardization of sample collection, isolation and analysis methods in extracellular vesicle research. J. Extracell Vesicles 2, 1. https://doi.org/10.3402/jev.v2i0.20360 (2013). 
15. Lasser, C. et al. Human saliva, plasma and breast milk exosomes contain RNA: uptake by macrophages. J Transl Med. 9, 9. https ://doi.org/10.1186/1479-5876-9-9 (2011).

16. Nielsen, M. J., Moller, H. J. \& Moestrup, S. K. Hemoglobin and heme scavenger receptors. Antioxid. Redox Signal. 12(2), 261-273 (2010).

17. Tolosano, E., Fagoonee, S., Morello, N., Vinchi, F. \& Fiorito, V. Heme scavenging and the other facets of hemopexin. Antioxid. Redox Signal. 12(2), 305-320 (2010).

18. Regal, J. F., Gilbert, J. S. \& Burwick, R. M. The complement system and adverse pregnancy outcomes. Mol. Immunol. 67(1), 56-70 (2015).

19. Shimomura, R. et al. Alpha-2-macroglobulin as a promising biological marker of endothelial function. J. Atheroscler. Thromb. 25(4), 350-358 (2018).

\section{Author contributions}

J.A.T., B.R.A.R. and M.G.S. conceived the study and participated in the study design. J.A.T. and B.R.A.R. wrote the manuscript. J.A.T. and S.A.A. conducted the experiments shown in Figs. $1 \mathrm{~b}$ and $2 \mathrm{a}-\mathrm{c}$. N.M.B., J.A.T., B.R.A.R. and J.C.S. conducted the experiments shown in Fig. 1a. B.R.A.R. conducted the experiments shown in Fig. 1c. All authors reviewed and edited the manuscript.

\section{Funding}

This work was supportes by São Paulo Research Foundation (FAPESP), Grants\#2016/16618-1 and 2019/17279-4.

\section{Competing interests}

The authors declare no competing interests.

\section{Additional information}

Supplementary information is available for this paper at https://doi.org/10.1038/s41598-020-73772-z.

Correspondence and requests for materials should be addressed to M.G.S.

Reprints and permissions information is available at www.nature.com/reprints.

Publisher's note Springer Nature remains neutral with regard to jurisdictional claims in published maps and institutional affiliations.

(c) (i) Open Access This article is licensed under a Creative Commons Attribution 4.0 International License, which permits use, sharing, adaptation, distribution and reproduction in any medium or format, as long as you give appropriate credit to the original author(s) and the source, provide a link to the Creative Commons licence, and indicate if changes were made. The images or other third party material in this article are included in the article's Creative Commons licence, unless indicated otherwise in a credit line to the material. If material is not included in the article's Creative Commons licence and your intended use is not permitted by statutory regulation or exceeds the permitted use, you will need to obtain permission directly from the copyright holder. To view a copy of this licence, visit http://creativecommons.org/licenses/by/4.0/.

(C) The Author(s) 2020 